Article

\title{
Impact of Wind Electricity Forecasts on Bidding Strategies
}

\author{
Cristina Ballester ${ }^{1}$ and Dolores Furió ${ }^{2, *}$ \\ 1 Bionline, 46980 Paterna, Spain; cristina.ballester.ch@gmail.com \\ 2 Department of Financial Economics, Universitat de València, 46010 València, Spain \\ * Correspondence: m.dolores.furio@uv.es
}

Received: 16 June 2017; Accepted: 25 July 2017; Published: 1 August 2017

\begin{abstract}
The change in the generation mix from conventional electricity sources to renewables has important implications for bidding behaviour and may have an impact on prices. The main goal of this work is to discover the role played by expected wind production, together with other relevant factors, in explaining the day-ahead market price through a data panel model. The Spanish market, given the huge increase in wind generation observed in the last decade, has been chosen for this study as a paradigmatic example. The results obtained suggest that wind power forecasts are a new key determinant for supply market participants when bidding in the day-ahead market. We also provide a conservative quantification of the effect of such trading strategies on marginal prices at an hourly level for a specific year in the sample. The consequence has been an increase in marginal price to levels higher than what could be expected in a context with notable wind penetration. Therefore, the findings of this work are of interest to practitioners and regulators and support the existence of a wind risk premium embedded in electricity prices to compensate for the uncertainty of wind production.
\end{abstract}

Keywords: day-ahead electricity market; renewables; strategic bidding

\section{Introduction}

Because of deregulation, the price for electricity has come to be determined by competitive bidding by producers and consumers in the wholesale day-ahead market, where an auction system is generally followed. The electricity supply function is discontinuous and increases with the level of demand. The resulting price from the auction, the so-called marginal price, corresponds to the highest price offered by the supply side from those accepted to satisfy demand. The offered prices to sell electricity will, in turn, depend on production costs and these significantly differ among the generation technologies. Therefore, the generation mix of a specific market area, among other factors, will likely condition the resulting marginal prices and the success of a given market design. Establishing the factors affecting price is crucial for all market participants for obtaining accurate forecasts when planning production and consumption, or when designing hedging strategies to face the price variation risk to which their positions are exposed.

Due to greater climate awareness, the inclusion of renewable production in the electricity system is a goal in most countries. Apart from the promotion of renewable generation, another measure taken to fight climate change has been the creation of carbon emission markets. The mechanism works as follows. At the end of each year, firms must deliver an equivalent number of allowances for their excess emissions. Firms are then provided with a number of emission allowances that depend on their pollution levels (derived from their production). Firms that need to increase their volume of emissions must have—or buy—the corresponding permits in the carbon emissions market. Within this new framework, in addition to input costs, market participants may have internalised the expected future carbon prices and wind production forecasts into their decision-making process when designing their bidding. 
In the Spanish case, the development and integration of renewable electricity production in the electricity market has been a target for the regulator over the last decade. Tables 1 and 2 show the annual figures for installed power capacity and electrical energy in Spain per generation technology from 2007 to 2013. These tables show that installed wind power capacity increased around $68 \%$ in the mentioned interval, whereas the amount of wind generation grew by $98 \%$ and reached $20 \%$ of the overall generation during 2013.

Table 1. Installed power capacity (MW) from 2007 to 2013.

\begin{tabular}{ccccccccc}
\hline Technology & $\mathbf{2 0 0 7}$ & $\mathbf{2 0 0 8}$ & $\mathbf{2 0 0 9}$ & $\mathbf{2 0 1 0}$ & $\mathbf{2 0 1 1}$ & $\mathbf{2 0 1 2}$ & $\mathbf{2 0 1 3}$ & $\mathbf{\Delta}$ \\
\hline Hydraulic & $17,507.30$ & $17,555.42$ & $17,555.42$ & $17,564.63$ & $17,571.99$ & $17,786.40$ & $17,785.98$ & $1.59 \%$ \\
Nuclear & 7729.11 & 7729.11 & 7729.11 & 7790.38 & 7865.99 & 7865.99 & 7865.99 & $1.77 \%$ \\
Coal & $11,894.79$ & $11,897.13$ & $11,897.13$ & $11,918.11$ & $12,158.11$ & $11,623.77$ & $11,641.23$ & $-2.13 \%$ \\
Fuel +gas & 7542.55 & 7161.10 & 5994.58 & 5145.44 & 3717.33 & 3428.73 & 3498.37 & $-53.62 \%$ \\
Combined cycle & $22,390.25$ & $23,105.03$ & $24,503.01$ & $27,146.39$ & $27,171.21$ & $27,206.47$ & $27,206.47$ & $21.51 \%$ \\
Other Hydraulic & 1871.49 & 1981.13 & 2022.91 & 2036.94 & 2042.40 & 2042.76 & 2105.70 & $12.51 \%$ \\
Wind & $13,667.82$ & $16,117.99$ & $18,869.00$ & $19,715.31$ & $21,174.90$ & $22,765.85$ & $23,002.30$ & $68.30 \%$ \\
Photovoltaic & 636.93 & 3352.55 & 3398.10 & 3838.45 & 4259.35 & 4559.53 & 4667.03 & $632.74 \%$ \\
Thermal Solar & 11.02 & 60.92 & 232.22 & 532.02 & 998.62 & 1950.02 & 2299.52 & $20,766.79 \%$ \\
Thermal Renewable & 588.17 & 634.57 & 782.12 & 821.13 & 887.07 & 975.41 & 980.05 & $66.63 \%$ \\
Thermal non & 6617.31 & 6870.29 & 7076.79 & 7240.04 & 7317.65 & 7280.7 & 7200.37 & $8.81 \%$ \\
Overall & $90,456.74$ & $96,465.24$ & $100,060.39$ & $103,748.84$ & $105,164.61$ & $107,485.64$ & $108,253.01$ & $19.67 \%$ \\
\hline & & Source: & www.ree.es. & & & & &
\end{tabular}

Table 2. Electric energy balance (GWh) from 2007 to 2013.

\begin{tabular}{ccccccccc}
\hline Technology & $\mathbf{2 0 0 7}$ & $\mathbf{2 0 0 8}$ & $\mathbf{2 0 0 9}$ & $\mathbf{2 0 1 0}$ & $\mathbf{2 0 1 1}$ & $\mathbf{2 0 1 2}$ & $\mathbf{2 0 1 3}$ & $\boldsymbol{\Delta}$ \\
\hline Hydraulic & $26,351.89$ & $21,428.20$ & $23,862.23$ & $38,652.87$ & $27,571.15$ & $19,454.73$ & $33,970.28$ & $13.01 \%$ \\
Nuclear & $55,102.47$ & $58,973.42$ & $52,761.04$ & $61,989.95$ & $57,731.36$ & $61,470.16$ & $56,827.39$ & $21.77 \%$ \\
Coal & $75,027.85$ & $49,646.83$ & $37,311.24$ & $25,478.01$ & $46,518.61$ & $57,661.60$ & $42,397.79$ & $16.24 \%$ \\
Fuel + gas & $10,784.48$ & $10,690.97$ & $10,056.01$ & 9552.96 & 7479.95 & 7541.49 & 7002.18 & $2.68 \%$ \\
Combined cycle & $72,307.14$ & $95,528.68$ & $82,239.39$ & $68,595.33$ & $55,139.86$ & $42,510.47$ & $28,671.93$ & $10.98 \%$ \\
Generation Consumption & -9634.62 & -9256.95 & -7999.11 & -7572.09 & -8128.95 & -8511.61 & -7053.51 & $-2.70 \%$ \\
Other hydraulic & 4126.50 & 4639.82 & 5454.07 & 6824.32 & 5295.99 & 4646.34 & 7102.20 & $2.72 \%$ \\
Wind & $27,611.65$ & $32,159.82$ & $38,252.83$ & $43,545.33$ & $42,465.29$ & $48,508.34$ & $54,713.25$ & $20.96 \%$ \\
Photovoltaic & 483.90 & 2497.96 & 6072.39 & 6422.77 & 7425.12 & 8202.09 & 8326.92 & $3.19 \%$ \\
Thermal solar & 7.63 & 15.38 & 129.82 & 691.62 & 1832.36 & 3444.13 & 4441.53 & $1.70 \%$ \\
Thermal renewable & 2588.97 & 2868.71 & 3317.34 & 3332.36 & 4317.99 & 4754.77 & 5074.70 & $1.94 \%$ \\
Cogeneration/others & $23,450.43$ & $26,721.15$ & $28,600.73$ & $30,973.32$ & $32,318.80$ & $33,767.25$ & $32,296.38$ & $12.37 \%$ \\
Net generation & $288,208.29$ & $295,913.98$ & $280,057.99$ & $288,486.75$ & $279,967.53$ & $283,449.75$ & $273,771.03$ \\
Pump consumption & -4432.29 & -3802.50 & -3794.19 & -4457.78 & -3214.96 & -5022.55 & -5957.85 \\
International Exchange balance & $-5,750.47$ & $-11,039.59$ & -8086.41 & -8332.68 & -6090.13 & $-11,199.95$ & -6732.14 \\
Overall & $278,025.54$ & $281,071.89$ & $268,177.39$ & $275,696.29$ & $270,662.44$ & $267,227.25$ & $261,081.04$ & $100.00 \%$ \\
\hline
\end{tabular}

Source: www.ree.es.

This sustained growth has meant a substantial change in the generation mix from conventional energy sources to renewables, and changes in the input proportions (among them, commodity prices) in electricity production costs. Moreover, the inclusion of new generating technologies in the generation mix may have altered the bidding strategies of generators and this may have an impact on prices.

A number of studies can be found in the literature that analyses the impact on spot prices of increasing renewable electricity production. A common pattern is detected that consists of a decrease in spot prices because of an increase in renewable production. This is due to the auction mechanism that is based on a merit order dispatch system (commonly used in electricity markets). Thus, sellers and buyers, the day before delivery day, submit quantity-price bids to the auction market. These bids are ranked by price and a marginal (or clearing) price is set when the supply aggregate curve matches the demand aggregate curve. Therefore, generators with lower marginal costs, such as renewables, can bid at lower prices-and these bids are normally positioned at the base of the merit-order and so are among the first bids matched in the auction. Therefore, an increase in renewables is expected to change and shift the supply curve in such a way that the spot price could be set at lower levels. This effect has been called in the literature the merit-order effect of renewables and has been highlighted in previous studies such as [1-8], among others (for a complete overview of past research on the merit-order effect of renewables, see [9]). A reduction in spot prices is welcomed by consumers and regulators. In fact, such a reduction will mean savings for household and industrial consumers, with the well-known 
implications in productivity gains. Such a reduction should also help to compensate for the economic effort required to finance support for renewables (in Europe, the most commonly adopted renewable support mechanism has been a feed-in-tariffs scheme in which the cost of the project is transferred to customers).

Agent-based models have been used in the literature to capture the complexity of the bidding strategy in electricity markets. In [10], an overview is presented of the techniques used by researchers to capture the dynamics in electricity markets that focuses on the agent-based models. The authors in [11] propose a model to maximise the benefits of a single generator that includes the expected behaviour of the rest of the participants and some of the characteristics of the electricity markets, such as the existence of congestion in the grid. In [12], an agent-based model is adjusted to the electricity market in Germany and it is found that the reduction in the spot price caused by renewables is higher when there are no transmission capacity constraints. The authors in [13] carry out an interesting analysis by studying the effect on day-ahead prices of bidding strategies from conventional generators. Taking into account forward trading, they state that market power depends on the amount of wind. The theoretical model of [13] is empirically tested in [4] by applying it to the British wholesale market to conclude that prices can be higher and more volatile in scenarios with market power. In [14], it is analysed the impact of day-ahead wind power forecasts on day-ahead electricity prices in the Western Danish price area of the Nord Pool's Elspot market. With the aim to find the optimal bidding strategy to maximise profits, the authors in [15] concluded that wind generation firms can increase their net earnings by improving wind forecasting accuracy. Focused on the Spanish electricity market, in [16] it is tested whether the bidding behaviour of large oil-fired thermal generators differed from that of small oil-fired thermal generators from 2002 to 2005.

Our approach is different as we are interested in distinguishing the effects by generation technology. Therefore, we study the impact on prices from bidding strategies by thermal, combined cycle, nuclear, hydroelectric, and renewable generation plants. To do so, we use a panel data model at an hourly level, similar to the panel data used in [8] for the Irish single electricity market (the authors in [8] model the spot price using an extension of seemingly unrelated regressions (SUR) for panel data models considering a system of $24 \mathrm{~h}$, one equation for each hour of the day from 2008 to 2013). The period under study, from 2007 to 2013, is characterised by the installation in Spain of a number of combined cycle and renewable source plants. Finally, an approximate quantification of the effect of wind production forecasts on the day-ahead market price is provided.

The main goal of this study is to identify the factors playing a specific role in the bidding behaviour by generators in the Spanish electricity day-ahead market. We are particularly interested in the role played by expected wind production as a new key determinant in this new context. The Spanish market has been chosen as a paradigmatic example due to the huge increase in wind generation in recent years. Together with expected wind production and based on the Spanish generation mix, we also control for other potential noteworthy factors, such as carbon and natural gas prices or reservoir levels.

Our findings support the existence of a wind risk premium embedded in electricity prices to compensate for the uncertainty of wind production. It is interesting that it is not wind farms who are behind this premium but the thermal (fuel oil, natural gas, and coal) and combined cycle plants who see how their production is being increasingly replaced by wind power when the wind blows.

This work is organised as follows. Section 2 describes the dataset used to embrace the analysis. Section 3 presents the methodology to detect the key factors explaining generator bidding and the results. Section 4 provides a quantification of the estimated impact of the expected wind production translated into bidding strategies on the marginal price by generation technology. Finally, Section 5 discusses the research results and gives some concluding remarks.

\section{Data}

The data set covers the period from 1 January 2010 to 31 December 2013 and consists of the following time-series data: 
- Quantity-price offers submitted by each generation unit to the day-ahead Spanish electricity market, to sell or buy energy, and by delivery hour (including matched and non-matched offers). This data is available on the website of Iberian Market Operator for Electricity, OMIE (www.omie.es).

- Wind power forecasts released by REE (www.ree.es) on an hourly basis. From all wind power forecasts available on an hourly basis for each delivery day-ahead hour, we carefully selected the last wind power forecasts available just before the deadline for submitting bids to the day-ahead auction markets. The historical series of data was directly received from REE.

- The day-ahead market marginal hourly prices were downloaded from the OMIE website (www.omie.es).

- National balance point natural gas day-ahead prices. The data was obtained from the Thomson Reuters database. Originally quoted in GBp/Therm, the data were transformed into euros/MWh for this study.

- European emission allowances (EUAs) futures prices corresponding to next December maturity with a daily frequency, obtained from the Thomson Reuters database.

- Hydroelectric reservoir data with a weekly frequency, downloaded from the Thomson Reuters database.

In short, the overall data set used in the present study includes 72 million records.

\section{Empirical Analysis}

This work aims at exploring the main factors affecting bidding by generators, and particularly the role of expected wind electricity production, since wind has recently entered the generation mix in many countries and expected wind production is becoming increasingly important. In areas where wind power has a significant share in the generation portfolio, variations in wind power generation can lead to substantial short-term changes in the overall supply function. Bids made by wind generators are usually among the first matched in the day-ahead auction market. This is due to the market mechanism itself, a merit-order dispatch procedure in which those technologies with lower variable costs (like nuclear, but also wind) can submit bids with lower prices and be among the first to be matched. Thus, if the wind blows, marginal prices are expected to decrease and generation technologies other than wind are likely to be (at least partly) replaced. Therefore, to optimise profits, both renewable and non-renewable generators are incentivised to behave strategically when submitting bids to an auction market that will also depend on wind power forecasts.

To embrace this analysis, it was necessary to deal with the data of the whole supply curve of the day-ahead market (all the offered prices of supply side participants) at an hourly level. For generator bidders, the day-ahead market is really made up of 24 auctions, one for each delivery hour. Bids have been grouped by generation technologies to disentangle differing plant-type strategies. According to the classification made on the OMIE webpage, bids from generators have been grouped into the following categories: combined cycle (CC); coal, fuel-gas and fuel-oil thermal plants (CT); hydroelectric $(\mathrm{CH})$; nuclear $(\mathrm{CN})$; and finally, renewable technologies, mainly wind and solar (CR). This latter category also includes bids coming from cogeneration and surplus production, but they are of residual importance because of their relatively scarce associated volume.

A panel data model has been chosen to make the most of the data. Generators submit bids for $24 \mathrm{~h}$ blocks at the same time, but the marginal price is set in a different auction for each delivery hour, and so hourly prices can be considered as separate contracts-but traded at the same time. A panel data model can capture both the unobserved effect (due to the delivery hour) and all the predictive information available at the single moment of bidding.

Figure 1 provides a general framework for helping the reader to follow the train of the argument through the methodology process. 


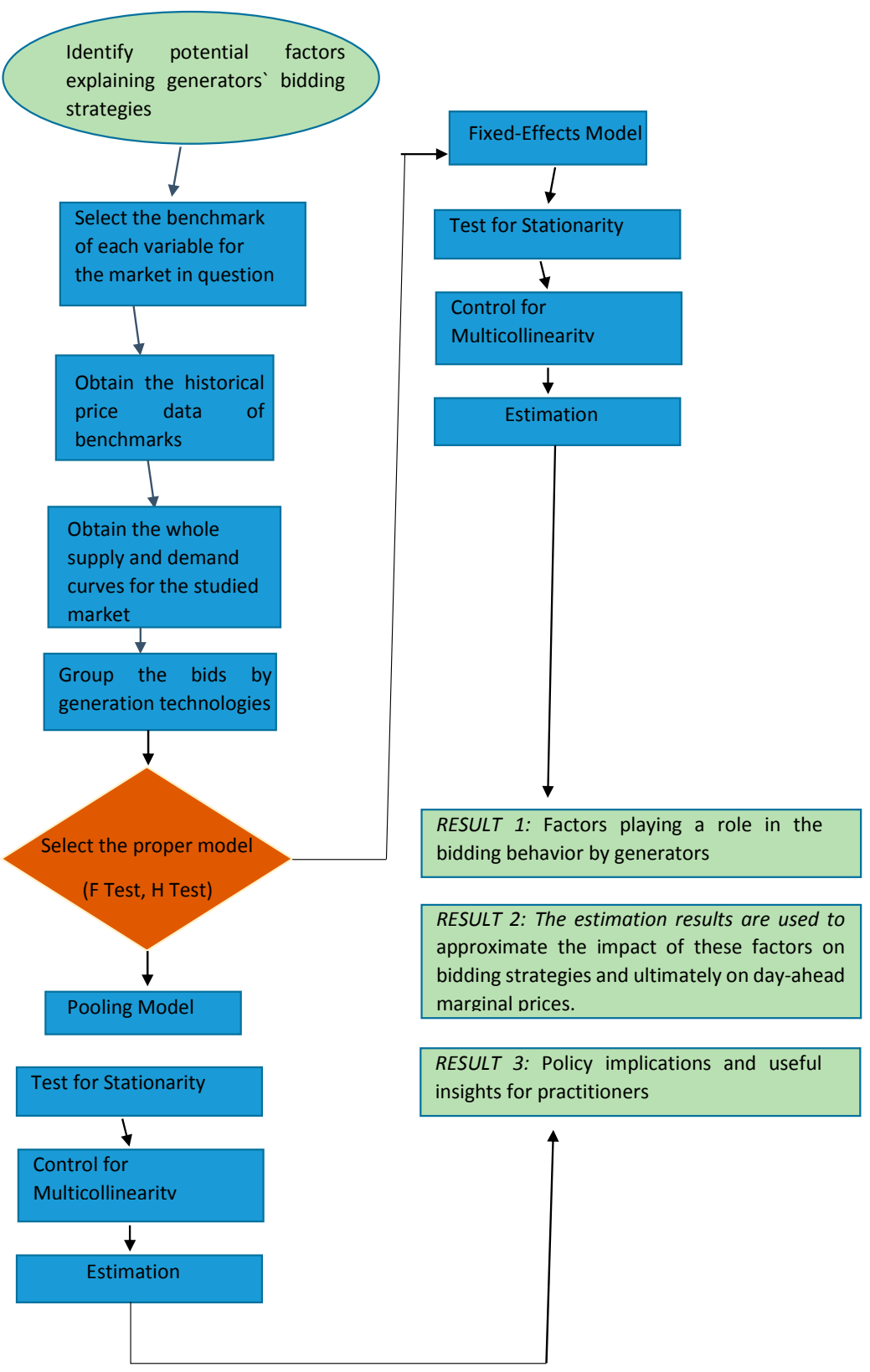

Figure 1. Flow diagram showing the general framework of the methodology used in the empirical exercise.

\subsection{Preliminary Analysis}

Firstly, for the good specification of the model, a check is made as to whether the coefficients representing cross-section-specific characteristics are equal for all cross-sections. To do so, we test for poolability across sections in the panel data model using an F test whose null hypothesis assumes homogeneous slope coefficients for all cross-sections (hours). As shown in Table 3a, the null is rejected for $\mathrm{CT}, \mathrm{CC}$, and $\mathrm{CH}$ generation technology plant groups, indicating there are cross-section-specific characteristics that depends on the delivery hour. Additionally, the Durbin-Wu-Haussman test ( $\mathrm{H}$ test) has been used to differentiate between two options to model the cross-section effect: a fixed-effects model or a random-effects model. Contrarily, the null cannot be rejected for $\mathrm{CN}$ and $\mathrm{CR}$, meaning that a pooling model is preferable when analysing these latter groups. The results of the $\mathrm{H}$ test confirm the previous result that the fixed-effects model (1) is more suitable than the random-effects model for 
$\mathrm{CT}, \mathrm{CC}$, and $\mathrm{CH}$. Therefore, for these generation technologies, the fixed-effects panel data model is adequate [17] and can be defined as follows:

$$
\begin{array}{r}
\mathrm{PMO}_{\mathrm{t}-1, \mathrm{t}, \mathrm{i}}=\beta * \mathrm{WPF}_{\mathrm{t}-1, \mathrm{t}, \mathrm{i}}+\gamma * \mathrm{DL}_{\mathrm{t}}+\phi * \mathrm{NG}_{\mathrm{t}-1} / \mathrm{EUA}_{\mathrm{t}-2}+\omega^{*} \mathrm{WR}_{\mathrm{t}-1}+\delta * \mathrm{PMO}_{\mathrm{t}-2, \mathrm{t}-1, \mathrm{i}}+\mathrm{u}_{\mathrm{t}, \mathrm{i}} \\
\mathrm{u}_{\mathrm{t}, \mathrm{I}}=\mathrm{v}_{\mathrm{i}}+\varepsilon_{\mathrm{t}, \mathrm{i}}
\end{array}
$$

where:

- $\mathrm{PMO}_{\mathrm{t}-1, \mathrm{t}, \mathrm{i}}$ is the average supply offered price by the group of generators sharing the same generation technology submitted on a particular day (day $t-1$ ) for delivering electricity at the day-ahead (day $t$ ) for the hour i.

- $\mathrm{WPF}_{\mathrm{t}-1, \mathrm{t}, \mathrm{i}}$ denotes the last available wind power forecast as made public by REE before the deadline for submitting bids to the day-ahead auction market for delivering electricity during hour $\mathrm{i}$ on day $\mathrm{t}$, and known at day $\mathrm{t}-1$.

- $\mathrm{DL}_{t}$ is a dummy variable that is equal to 1 if $t$ is a business day and 0 otherwise. It is included in the model to capture the business-day effect on electricity day-ahead prices.

- $\mathrm{NG}_{\mathrm{t}-1} / \mathrm{EUA}_{\mathrm{t}-2}$ is the ratio: national balance point natural gas day-ahead prices on day $\mathrm{t}-1$ divided by ICE ECX European emission allowances next December maturity closing futures prices at $\mathrm{t}-2$. Regarding the latter, we use lagged prices because the available closing prices at the closure time of the day-ahead auction market which takes place at $t-1$ (for delivering electricity at $t$ ) are those of the previous trading session, i.e., at $t-2$. We firstly considered the inclusion of natural gas and carbon emission price series as separate explanatory variables, but the higher correlation between them prevented us from doing so. We finally opted to use the series of the ratio carbon emission prices/natural gas prices to avoid multicollinearity problems.

- $\quad \mathrm{WR}_{\mathrm{t}-1}$ is the hydroelectric reservoirs on day $\mathrm{t}-1$.

- The stochastic component, $\mathrm{u}_{\mathrm{t}, \mathrm{i}}$, is a process made up of two components: $v_{\mathrm{i}}$, which is assumed to be independent during the days, although it allows for cross-sectional covariance between the hours, and $\varepsilon_{t, \mathrm{i}}$, which is the usual homoscedastic component, normally distributed $\mathrm{N}(0, \sigma)$. Indeed, it is the specification of a fixed-effects panel model in which the cross-section is the delivery hour $\mathrm{i}=1,2, \ldots, 24$.

As previously stated, the null hypothesis of poolability could not be rejected for $\mathrm{CN}$ and $\mathrm{CR}$ plant groups, which prevented us from using a panel data model as specified in (1) for these generator types. Contrarily, it is more appropriate in this case to use a pooling model for $\mathrm{CN}$ and $\mathrm{CR}$ plant groups, as follows:

$$
\mathrm{PMO}_{\mathrm{t}-1, \mathrm{t}, \mathrm{i}}=\alpha+\beta * \mathrm{WPF}_{\mathrm{t}-1, \mathrm{t}, \mathrm{i}}+\gamma * \mathrm{DL}_{\mathrm{t}}+\phi * \mathrm{NG}_{\mathrm{t}-1} / \mathrm{EUA}_{\mathrm{t}-2}+\omega * \mathrm{WR}_{\mathrm{t}-1}+\delta * \mathrm{PMO}_{\mathrm{t}-2, \mathrm{t}-1, \mathrm{i}}+\varepsilon_{\mathrm{t}, \mathrm{i}}
$$

which differs from (1) in the inclusion of an intercept, $\alpha$, which is the same for all cross-sections substituting the fixed-effects hourly components, $\mathrm{v}_{\mathrm{i}}$, and in that the stochastic component is a process made up of only one component, $\varepsilon_{t, i}$, the usual homoscedastic component, normally distributed $N(0, \sigma)$.

It is well known that regression models for non-stationarity variables give spurious results unless the series are cointegrated. Non-stationarity is at least as serious a problem for panel data sets as it is for aggregate data, since non-stationarity could cause spurious estimates when estimating static panel models, according to [18]. We use the unit root test proposed by [19] to test the stationarity of the dependent variable $\left(\mathrm{PMO}_{\mathrm{t}-1, \mathrm{t}, \mathrm{i}}\right)$. As is displayed in Table 3 , the null hypothesis of a lack of stationarity is rejected for all the generation technology plant groups. Furthermore, to control for multicollinearity, the variance inflation factors (VIF) have been obtained (Table 3b). In all cases, VIF is lower than 2.1, a level which is considered acceptable following [17]. 
Table 3. Panel data specification tests.

\begin{tabular}{|c|c|c|c|c|c|c|c|c|c|c|}
\hline & $\mathrm{CC}$ & & $\mathrm{CT}$ & & $\mathrm{CH}$ & & $\mathrm{CN}$ & & CR & \\
\hline (a) & Statistic & Sig. & Statistic & Sig. & Statistic & Sig. & Statistic & Sig. & Statistic & Sig. \\
\hline $\mathrm{F}$ test & 6.35 & $* * *$ & 18.25 & $* * *$ & 3.07 & $* * *$ & 0.38 & & 0.75 & \\
\hline $\mathrm{H}$ test & 539.07 & $* * *$ & 3537.80 & $* * *$ & 49.42 & $* * *$ & & & & \\
\hline MW test & 104.81 & $* * *$ & 1025.7 & $* * *$ & 410.33 & $* * *$ & 1142.1 & $* * *$ & 246.18 & $* * *$ \\
\hline (b) & VIF & & VIF & & VIF & & VIF & & VIF & \\
\hline $\mathrm{WPF}_{\mathrm{t}-1, \mathrm{t}, \mathrm{i}}$ & 1.096 & & 1.116 & & 1.128 & & 1.085 & & 1.087 & \\
\hline $\mathrm{DL}_{\mathrm{t}}$ & 1.000 & & 1.002 & & 1.000 & & 1.002 & & 1.001 & \\
\hline $\mathrm{NG}_{\mathrm{t}-1} / \mathrm{EUA}_{\mathrm{t}-2}$ & 1.640 & & 1.210 & & 1.306 & & 1.105 & & 1.370 & \\
\hline$W_{t-1}$ & 1.448 & & 1.121 & & 1.240 & & 1.077 & & 1.111 & \\
\hline $\mathrm{PMO}_{\mathrm{t}-2, \mathrm{t}-1, \mathrm{i}}$ & 2.064 & & 1.206 & & 1.440 & & 1.039 & & 1.300 & \\
\hline
\end{tabular}

(a) presents the results of the $\mathrm{F}$ test, and the Durbin-Wu-Haussman and Maddala-Wu tests. The $\mathrm{F}$ test is a poolability test and enables choosing between a fixed-effect panel data model and a pooling model. The null hypothesis is a homogeneous slope coefficient for all cross-sections (hours) indicating that a pooling model is preferred. The Durbin-Wu-Haussman test ( $\mathrm{H}$ test) is used to select between the existence of random or fixed effects in the panel data model with auxiliary regression and robust covariance estimators. The null hypothesis is that the random-effect estimation is preferred (consistent and more efficient). Finally, the Maddala-Wu test (MW test) is a unit root test for panel data. The null hypothesis is non-stationarity. The tests are performed for all technologies with the exception of the $\mathrm{H}$ test, which is only for combined cycle generators, thermal, and hydraulics. The significant codes (Sig.) are:

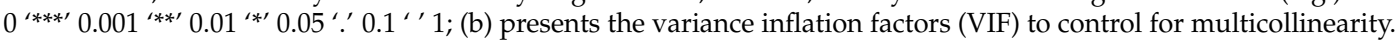
$\mathrm{WPF}_{\mathrm{t}-1, \mathrm{t}, \mathrm{i}}$ denotes the wind power forecast made public on day $\mathrm{t}-1$ just before the deadline for submitting bids to the day-ahead market auction for delivering electricity during hour $i$ on day $t ; L_{t}$ is a dummy variable that equals 1 if $\mathrm{t}$ is a business day, and 0 , otherwise; $\mathrm{NG}_{\mathrm{t}-1}$ is the British natural day-ahead trade close price on day $\mathrm{t}-1$; $\mathrm{EUA}_{\mathrm{t}-2}$ refers to the European emission allowances next December maturity futures closing prices on day $\mathrm{t}-2$; $W_{t-1}$ denotes the hydroelectric water reservoirs on day $t-1$, and $\mathrm{PMO}_{t-2, t-1, i}$ is the average supply price offered by the group of generators the day-before $($ day $t-2)$ for delivering electricity on the day-ahead (day $t-1)$ during hour i. combined cycle $(\mathrm{CC})$, thermal $(\mathrm{CT})$, hydraulics $(\mathrm{CH})$, nuclear $(\mathrm{CN})$ and renewable $(\mathrm{CR})$.

Before estimation, it is interesting to take a brief look at the main descriptive statistics for the variables used in the present study, which are displayed in Table 4. As expected, average offered prices to sell electricity from low variable cost plants, such as $\mathrm{CN}$ or $\mathrm{CR}$, are considerably lower than those offered by higher variable cost plants, namely, CC or CT. This is true for the four quantiles of the bid-price distributions.

The range $(R)$ is calculated as the difference between the largest and smallest offered prices and indicates the array of prices at which generators of the same technology have submitted their bids to the auction during the studied sample. This measure of variation gives us an idea about the most actively strategic plant groups, namely, those groups that are flexible enough to adapt their bidding to expected supply and demand levels. Thereby, the highest range is obtained for CC plants (90.11), followed by CT plants (82.52), CH plants (79.27), CN plants (45.30) and CR plants (27.60). However, it is noteworthy that the range measure has the disadvantage that it is based on only two observations and fails to show how the other observations are arranged between them. The interquartile range (IR), calculated as the difference between the third and first quartiles, overcomes this drawback, indicating the spread of the middle $50 \%$ of the distribution. Thus, the interquartile range is again the highest for CC plants (23.24), but now followed at a greater distance by CH plants (11.58), CT plants (8.71), $\mathrm{CN}$ plants (4.55), and CR plants (3.78). Note that these are still conservative indicators, since we are dealing with average offered prices by generation source and both the range and interquartile range for each generator are expected to be higher.

Another statistic that is frequently used to measure variability in prices is standard deviation. From Table 4, the highest value of standard deviation corresponds to bids from CC plants (15.27), followed by $\mathrm{CH}$ plants (10.19), and by CT plants (8.69). The standard deviations of CN and CR plants are remarkably lower (respectively, 3.87 and 4.77). The small standard deviation of the ratio NG/EUA (2.06) needs to be highlighted, as well as the large standard deviation of the wind power forecasts (2792), consistent with the variability of wind production that often makes it difficult to predict. 
Table 4. Descriptive summary statistics (2010-2013).

\begin{tabular}{cccccccccc}
\hline & Min. & 1st Qu. & Median & Mean & 3rd Qu. & Max & Sd & R & IR \\
\hline $\mathrm{PMO}_{\mathrm{e}}=\mathrm{CC}$ & 30.03 & 49.59 & 66.19 & 63.35 & 72.83 & 120.14 & 15.27 & 90.11 & 23.24 \\
$\mathrm{PMO}_{\mathrm{e}}=\mathrm{CT}$ & 42.05 & 53.99 & 58.35 & 59.20 & 62.70 & 124.57 & 8.68 & 82.52 & 8.71 \\
$\mathrm{PMO}_{\mathrm{e}}=\mathrm{CH}$ & 21.74 & 48.70 & 55.55 & 54.12 & 60.28 & 101.01 & 10.19 & 79.27 & 11.58 \\
$\mathrm{PMO}_{\mathrm{e}}=\mathrm{CN}$ & 00.00 & 18.20 & 20.22 & 20.62 & 22.75 & 45.30 & 3.87 & 45.30 & 4.55 \\
$\mathrm{PMO}_{\mathrm{e}}=\mathrm{CR}$ & 05.62 & 19.40 & 21.51 & 20.31 & 23.18 & 33.22 & 4.77 & 27.60 & 3.78 \\
$\mathrm{WPF}_{\mathrm{t}-1, \mathrm{t}, \mathrm{i}}$ & 508 & 3124 & 4776 & 5289 & 6984 & 16264 & 2791.99 & $15,756.00$ & 3860.00 \\
$\mathrm{NG}_{\mathrm{t}-1} / \mathrm{EU} A_{\mathrm{t}-2}$ & 0.73 & 1.35 & 2.85 & 3.12 & 4.64 & 10.11 & 2.06 & 9.38 & 3.29 \\
$\mathrm{WR}_{\mathrm{t}-1}$ & 47.30 & 65.10 & 77.70 & 73.03 & 81.60 & 89.20 & 11.91 & 41.90 & 16.50 \\
\hline
\end{tabular}

Descriptive summary statistics of the variables included in the analysis: $\mathrm{PMO}_{\mathrm{e}}$ is the average supply price offered by the group e of generators sharing the same generation technology submitted on a particular day (day $t-1)$ for delivering electricity on the day-ahead (day $t$ ) during hour $\mathrm{i} ; \mathrm{WPF}_{\mathrm{t}-1, \mathrm{t}, \mathrm{i}}$ denote the wind power forecast made public just before the deadline to submit bids to the day ahead market on day $t-1$ for delivering electricity during hour $\mathrm{i}$ on day $\mathrm{t} ; \mathrm{NG}_{\mathrm{t}-1}$ is the British natural day-ahead trade close price on day $\mathrm{t}-1 ; \mathrm{EUA}_{\mathrm{t}-2}$ refers to the European emission allowances next December maturity futures closing prices on day $t-2\left(\mathrm{EUA}_{\mathrm{t}-1}\right) ; \mathrm{WR}_{\mathrm{t}-1}$ denotes the hydroelectric water reservoirs on day $\mathrm{t}-1$. Combined cycle generators $(\mathrm{CC})$, thermal $(\mathrm{CT})$, hydraulics $(\mathrm{CH})$, nuclear $(\mathrm{CN})$ and renewable $(\mathrm{CR})$. [Min = minimun; $\mathrm{Max}=$ maximum; median; mean; 1 st $\mathrm{Qu} .=25 \%$ quantile; $3 \mathrm{rd} \mathrm{Qu} .=75 \%$ quantile; $\mathrm{Sd}$ = standard deviation; $\mathrm{R}=$ range; $\mathrm{IR}$ = interquartile range].

Table 5 displays the average prices offered by generation technology and by hour and distinguishing between business and non-business days. Interestingly, the average offered prices by $\mathrm{CC}$ and $\mathrm{CT}$ are remarkably higher in the early hours of the day, more specifically, in the first eight hours, regardless of whether it is a business or a non-business day.

Table 5. Average supply price offered by technologies, hours, and business/non-business days. Combined cycle $(\mathrm{CC})$, thermal $(\mathrm{CT})$, hydraulics $(\mathrm{CH})$, nuclear $(\mathrm{CN})$ and renewable $(\mathrm{CR})$.

\begin{tabular}{|c|c|c|c|c|c|c|c|c|c|c|c|c|c|c|c|}
\hline \multirow[b]{2}{*}{ Hour } & \multicolumn{5}{|c|}{ Overall } & \multicolumn{5}{|c|}{ Business Day } & \multicolumn{5}{|c|}{ Non-Business Day } \\
\hline & $\mathrm{CC}$ & CT & $\mathrm{CH}$ & $\mathrm{CN}$ & CR & $\mathrm{CC}$ & CT & $\mathrm{CH}$ & $\mathrm{CN}$ & CR & $\mathrm{CC}$ & CT & $\mathrm{CH}$ & $\mathrm{CN}$ & CR \\
\hline 1 & 69.53 & 67.36 & 4.56 & 20.24 & 23.67 & 68.87 & 66.98 & 54.78 & 20.24 & 23.62 & 71.05 & 68.24 & 54.04 & 20.26 & 23.80 \\
\hline 2 & 73.12 & 66.81 & 54.85 & 0.62 & 21.78 & 72.60 & 6.62 & 55.03 & & & 74.31 & & 54.44 & 0.58 & 21.82 \\
\hline 3 & 72.50 & 67.07 & 55.25 & 0.57 & 21.70 & 72.21 & 7.11 & 55.36 & 20.60 & 21.66 & 73.17 & 66.99 & 55.01 & 0.51 & 21.79 \\
\hline 4 & 72.95 & 66.60 & 55.39 & 20.51 & 21.74 & 72.60 & 6.60 & 55.47 & 20.53 & 21.71 & 73.75 & 66.60 & 55.21 & 0.44 & 21.81 \\
\hline 5 & 71.47 & 64.63 & 55.42 & 20.42 & 21.79 & 71.18 & & 55.50 & & & 72.14 & 64.71 & & & 21.86 \\
\hline 6 & 71.08 & & & 20.40 & & & & & & & & & & & \\
\hline 7 & & 59.9 & 55.7 & & & & & & & & & & & & \\
\hline 8 & .34 & 56.8 & 55. & .36 & 20 & 64. & & 55.39 & & & & & & & \\
\hline 9 & .22 & 56.5 & 54. & .43 & 19. & 59. & & 54.62 & & & 28 & & & & \\
\hline 10 & .72 & 56.0 & 53.9 & .56 & 19.3 & 58. & 2 & 53.74 & 20.66 & 0 & 61.54 & 56.58 & & 36 & \\
\hline 11 & 59.57 & 55.65 & 53.48 & 20.63 & 19.36 & 58.95 & 55.41 & 53.26 & 20.71 & 19.37 & 60.96 & 56.19 & 53. & 20.46 & 19. \\
\hline 12 & & 54.9 & & 20.62 & 19. & & & 53.0 & 20. & & 60. & 43 & & & \\
\hline 13 & 59.49 & 55.81 & 53.25 & 20.70 & 19.16 & 58.92 & 55.57 & 53.06 & 20.80 & 19.15 & 60.78 & 56.34 & 53.69 & 48 & 19.17 \\
\hline 14 & 59.49 & 57.89 & 53.35 & 20.74 & 19.04 & 58.93 & 57.61 & 53.23 & 20.84 & 19.03 & 60.77 & 58.52 & 53.62 & & 19.07 \\
\hline 15 & 59.59 & 57.95 & 53.51 & 20.81 & 18.94 & 59.06 & 57.67 & 53.41 & 20.93 & 18.89 & 60.80 & 58 & 53.73 & & 19.04 \\
\hline 16 & 59.60 & 57.98 & 53.61 & 20.86 & 18.91 & 59.05 & 57.68 & 53.50 & 20.96 & 18.86 & 60.84 & 58.66 & 53.84 & 20.62 & 19.02 \\
\hline 17 & 59.56 & 58.12 & 53.76 & 20.87 & 18.95 & 59.01 & & 53.65 & 20.97 & 18.93 & 60.81 & & & 20.65 & 19.00 \\
\hline 18 & 59.50 & 58.16 & 53.87 & 20.84 & & & & 53.78 & & & 60.72 & & & 20.61 & 19.10 \\
\hline 19 & & 58.33 & 53.8 & 20.86 & 19.35 & & & & & & 60.40 & & & & 19.33 \\
\hline 20 & & 58.4 & 53.7 & 20.81 & 19.6 & 58. & & 53.79 & & 19.6 & 60.36 & 0 & & & \\
\hline 21 & & 58.27 & 53.2 & 20.74 & 19.9 & 58. & 58.01 & 53.35 & 20.80 & 19.96 & 60.30 & 58.85 & 52.86 & 20.59 & 20.05 \\
\hline 22 & & 57.70 & 52.9 & 20.76 & 20.3 & 58. & 57.49 & 53.16 & 20.81 & 20.28 & 60.32 & 58.15 & 52.52 & 20.65 & 20.47 \\
\hline 23 & & & & 20.69 & & & & & & & 60.65 & & 52.57 & 20.56 & 20.70 \\
\hline 24 & 61.51 & 57.92 & 53.53 & 20.48 & 20.38 & 61.25 & 57.71 & 53.82 & 20.58 & 20.27 & 62.09 & 58.41 & 52.89 & 20.27 & 20.62 \\
\hline
\end{tabular}

To see whether those differences are statistically significant, a test for equality of means between the block of the first eight hours of the day and the remaining block of hours is conducted. Table 6 presents the results in three panels, distinguishing between: the overall sample (a); the sample only including business-day observations (b); and the sample including only non-business-day observations (c). As can be observed, the average offered prices for the first eight hours of the day are significantly 
different from those for the remaining hours for all the considered generation technologies. From (a), it is noticeable that the average offered price for the first eight hours is remarkably higher than the average offered prices for the block of the remaining hours in the cases of CT and CC. This difference is just slightly (but significantly) higher in the case of $\mathrm{CH}$ and $\mathrm{CR}$ and lower in the case of $\mathrm{CN}$. These results remain the same when moving to (b) (business days) and (c) (non-business days), with the only exception being CR (that does not offer a significantly different price for delivery hours on non-business days).

Table 6. Equality of means test.

\begin{tabular}{|c|c|c|c|c|c|c|c|c|c|c|}
\hline & $\mathrm{CC}$ & & CT & & $\mathrm{CH}$ & & $\mathrm{CN}$ & & CR & \\
\hline (a) & {$[1-8 \mathrm{~h}]$} & [9-24 h] & {$[1-8 \mathrm{~h}]$} & [9-24 h] & {$[1-8 \mathrm{~h}]$} & [9-24 h] & {$[1-8 \mathrm{~h}]$} & [9-24 h] & [1-8 h] & [9-24 h] \\
\hline Mean & 70.7 & 59.6 & 64.0 & 57.4 & 55.3 & 53.5 & 20.4 & 20.7 & 22.0 & 19.5 \\
\hline t-statistic & 61.0 & & 56.6 & & 14.5 & & -6.2 & & 44.8 & \\
\hline Sig. & $* * *$ & & $* * *$ & & $* * *$ & & $* * *$ & & $* * *$ & \\
\hline \multicolumn{11}{|l|}{ (b) } \\
\hline [Business days] & {$[1-8 \mathrm{~h}]$} & [9-24 h] & {$[1-8 \mathrm{~h}]$} & [9-24h] & {$[1-8 \mathrm{~h}]$} & {$[9-24 \mathrm{~h}]$} & {$[1-8 \mathrm{~h}]$} & [9-24 h] & {$[1-8 \mathrm{~h}]$} & {$[9-24 \mathrm{~h}]$} \\
\hline Mean estimates & 70.1 & 59.1 & 63.8 & 57.1 & 55.4 & 53.5 & 20.4 & 20.8 & 21.9 & 19.5 \\
\hline t-statistic & 51 & & 47.7 & & 13.5 & & -6.3 & & 37.3 & \\
\hline Sig. & $* * *$ & & $* * *$ & & $* * *$ & & $* * *$ & & $* * *$ & \\
\hline \multicolumn{11}{|l|}{ (c) } \\
\hline Non-business days & {$[1-8 \mathrm{~h}]$} & [9-24 h] & {$[1-8 \mathrm{~h}]$} & [9-24 h] & {$[1-8 \mathrm{~h}]$} & {$[9-24 \mathrm{~h}]$} & {$[1-8 \mathrm{~h}]$} & [9-24 h] & {$[1-8 \mathrm{~h}]$} & {$[9-24 \mathrm{~h}]$} \\
\hline Mean & 71.9 & 60.9 & 64.5 & 57.9 & 54.8 & 53.6 & 20.3 & 20.5 & 21.9 & 19.5 \\
\hline t-statistic & 33.6 & & 30.6 & & 5.9 & & -1.8 & & 24.7 & \\
\hline Sig & $* * *$ & & $* * *$ & & $* * *$ & & . & & $* * *$ & \\
\hline
\end{tabular}

Equality of means test: A test for equality of means in the bid prices for the block of the first eight hours and the block of the remaining hours was conducted: (a) presents the results for the overall sample, distinguishing by generation technology; (b) and (c) present the results focusing on the business (non-business) days. Combined cycle (CC), thermal (CT), hydraulics $(\mathrm{CH})$, nuclear $(\mathrm{CN})$ and renewable $(\mathrm{CR})$. The sample mean estimates in samples are

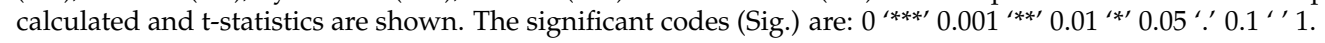

\subsection{Estimation Results}

The panel data estimation results are presented in Table 7 (for CC, CT, and $\mathrm{CH}$ generation technologies) and in Table 8 (for $\mathrm{CN}$ and CR generation technologies).

The standard errors have been obtained following [20], since they are robust to serial correlation over time and specifically convenient when cross-sectional dependence is present, according to [21]. To reinforce the robustness of the results, following [22], the standard errors have also been calculated using a robust covariance matrix that controls for heteroskedasticity and serial (cross-sectional) correlation for fixed-effect models. Moreover, a wild cluster bootstrapped t-statistics estimation for cluster-robust standard errors in fixed-effect models was conducted ([23]) that provides asymptotic refinement when the number of clusters is fewer than 30. A double-clustering robust covariance matrix estimation for panel models was also conducted. All these approaches led us to the same results as those presented in the main text and so they hold up with remarkable consistency. The obtained R-squared is above $90 \%$ for $\mathrm{CC}, \mathrm{CH}$, and $\mathrm{CR}$-and above $60 \%$ for all considered generation technologies except CN (54\%). 
Table 7. Panel data fixed-effects estimation.

\begin{tabular}{|c|c|c|c|c|c|c|c|c|c|}
\hline \multirow[b]{2}{*}{ Parameter } & \multicolumn{3}{|c|}{$\mathrm{CC}$} & \multicolumn{3}{|c|}{$\mathrm{CT}$} & \multicolumn{3}{|c|}{$\mathrm{CH}$} \\
\hline & Value & t-Statistic & Sig. & Value & $\mathrm{t}$-Statistic & Sig. & Value & $\mathrm{t}$-Statistic & Sig. \\
\hline$\beta$ & 0.00014 & 8.00 & $* * *$ & 0.00034 & 8.09 & $* * *$ & -0.00016 & -5.99 & $* * *$ \\
\hline$\gamma$ & -1.33477 & -11.93 & $* * *$ & -1.16985 & -8.85 & $* * *$ & 0.14415 & 1.30 & \\
\hline$\phi$ & 0.09844 & 3.35 & $* * *$ & -0.34550 & -5.64 & $* * *$ & 0.14921 & 3.91 & $* * *$ \\
\hline$\omega$ & -0.01561 & -3.50 & $* * *$ & 0.04181 & 5.31 & $* * *$ & -0.01644 & -3.94 & $* * *$ \\
\hline$\delta$ & 0.95877 & 195.46 & $* * *$ & 0.76171 & 36.94 & $* * *$ & 0.94246 & 83.82 & $* * *$ \\
\hline $\mathrm{V}_{1}$ & 3.87672 & 6.68 & $* * *$ & 13.05886 & 10.36 & $* * *$ & 4.67539 & 5.54 & $* * *$ \\
\hline $\mathrm{V}_{2}$ & 4.03756 & 6.78 & $* * *$ & 12.96304 & 10.35 & $* * *$ & 4.67676 & 5.54 & $* * *$ \\
\hline $\mathrm{V}_{3}$ & 4.02245 & 6.79 & $* * *$ & 13.05470 & 10.37 & $* * *$ & 4.68570 & 5.53 & $* * *$ \\
\hline $\mathrm{V}_{4}$ & 4.06191 & 6.84 & $* * *$ & 12.97138 & 10.36 & $* * *$ & 4.67988 & 5.52 & $* * *$ \\
\hline $\mathrm{V}_{5}$ & 4.01183 & 6.83 & $* * *$ & 12.53579 & 10.29 & $* * *$ & 4.66785 & 5.51 & $* * *$ \\
\hline $\mathrm{V}_{6}$ & 4.00611 & 6.84 & $* * *$ & 12.20608 & 10.23 & $* * *$ & 4.66998 & 5.51 & $* * *$ \\
\hline $\mathrm{V}_{7}$ & 3.95008 & 6.82 & $* * *$ & 11.47737 & 10.07 & $* * *$ & 4.67175 & 5.51 & $* * *$ \\
\hline $\mathrm{V}_{8}$ & 3.77923 & 6.72 & $* * *$ & 10.72787 & 9.88 & $* * *$ & 4.63409 & 5.50 & $* * *$ \\
\hline $\mathrm{V}_{9}$ & 3.57346 & 6.60 & $* * *$ & 10.65872 & 9.86 & $* * *$ & 4.60065 & 5.50 & $* * *$ \\
\hline $\mathrm{V}_{10}$ & 3.55247 & 6.59 & $* * *$ & 10.54579 & 9.83 & $* * *$ & 4.56004 & 5.50 & $* * *$ \\
\hline $\mathrm{V}_{11}$ & 3.53845 & 6.57 & $* * *$ & 10.43079 & 9.79 & $* * *$ & 4.54366 & 5.51 & $* * *$ \\
\hline $\mathrm{V}_{12}$ & 3.52077 & 6.53 & $* * *$ & 10.22657 & 9.72 & $* * *$ & 4.55033 & 5.52 & $* * *$ \\
\hline $\mathrm{V}_{13}$ & 3.50304 & 6.50 & $* * *$ & 10.39007 & 9.76 & $* * *$ & 4.56618 & 5.53 & $* * *$ \\
\hline $\mathrm{V}_{14}$ & 3.48723 & 6.47 & $* * *$ & 10.84854 & 9.88 & $* * *$ & 4.59104 & 5.54 & $* * *$ \\
\hline $\mathrm{V}_{15}$ & 3.47714 & 6.44 & $* * *$ & 10.82819 & 9.87 & $* * *$ & 4.61774 & 5.55 & $* * *$ \\
\hline $\mathrm{V}_{16}$ & 3.46436 & 6.41 & $* * *$ & 10.80613 & 9.86 & $* * *$ & 4.63886 & 5.56 & $* * *$ \\
\hline $\mathrm{V}_{17}$ & 3.45504 & 6.40 & $* * *$ & 10.82202 & 9.86 & $* * *$ & 4.65649 & 5.56 & $* * *$ \\
\hline $\mathrm{V}_{18}$ & 3.44887 & 6.39 & $* * *$ & 10.82314 & 9.86 & $* * *$ & 4.66564 & 5.56 & $* * *$ \\
\hline $\mathrm{V}_{19}$ & 3.43959 & 6.38 & $* * *$ & 10.85556 & 9.87 & $* * *$ & 4.66610 & 5.56 & $* * *$ \\
\hline $\mathrm{V}_{20}$ & 3.44031 & 6.38 & $* * *$ & 10.87333 & 9.87 & $* * *$ & 4.66328 & 5.57 & $* * *$ \\
\hline $\mathrm{V}_{21}$ & 3.44165 & 6.38 & $* * *$ & 10.84575 & 9.87 & $* * *$ & 4.63425 & 5.57 & $* * *$ \\
\hline $\mathrm{V}_{22}$ & 3.44362 & 6.39 & $* * *$ & 10.7137 & 9.83 & $* * *$ & 4.61469 & 5.56 & $* * *$ \\
\hline $\mathrm{V}_{23}$ & 3.46485 & 6.41 & $* * *$ & 10.84151 & 9.87 & $* * *$ & 4.61226 & 5.56 & $* * *$ \\
\hline $\mathrm{V}_{24}$ & 3.54811 & 6.48 & $* * *$ & 10.80414 & 9.86 & $* * *$ & 4.63071 & 5.56 & $* * *$ \\
\hline R-squared & 0.95756 & & & 0.68220 & & & 0.93162 & & \\
\hline Adj.R-squared & 0.95753 & & & 0.68194 & & & 0.93157 & & \\
\hline
\end{tabular}

Panel data fixed-effects estimation: $\mathbf{P M O}_{t-1, t, i}=\beta^{*} \mathbf{W P F}_{t-1, t, i}+\gamma^{*} \mathbf{D L}_{t}+\phi^{*} \mathbf{N G}_{t-1} / \mathbf{E U A}_{\mathrm{t}-2}+\omega^{*} \mathbf{W R}_{t-1}+$ $\delta^{*} \mathbf{P M O}_{\mathbf{t}-2, \mathbf{t}-1, \mathbf{i}}+\mathbf{u}_{\mathrm{t}, \mathrm{i}} ; \mathbf{u}_{\mathrm{t}, \mathbf{i}}=\mathbf{v}_{\mathbf{i}}+\varepsilon_{\mathrm{t}, \mathbf{i}} \mathbf{( 1 )}$. Fixed-effects panel linear models estimation with nonparametric robust covariance matrix estimators with cross-sectional and serial correlation ([20]). $\mathrm{PMO}_{\mathrm{t}-1, \mathrm{t}, \mathrm{i}}$ is the average supply price offered by the group of generators sharing the same generation technology submitted on a particular day (day $\mathrm{t}-$ 1) for delivering electricity on the day-ahead (day $t$ ) during hour $i ; \mathrm{WPF}_{t-1, t, i}$ denotes the wind power forecast made public on day $\mathrm{t}-1$ just before the deadline for submitting bids to the day-ahead market auction for delivering electricity during hour i on day $\mathrm{t} ; \mathrm{DL}_{\mathrm{t}}$ is a dummy variable that equals 1 if $\mathrm{t}$ is a business day, and 0 , otherwise; $\mathrm{NG}_{t-1}$ is the British natural day-ahead trade close price on day $\mathrm{t}-1 ; \mathrm{EUA}_{\mathrm{t}-2}$ refers to the European emission allowances next December maturity futures closing prices on day $t-2$; WRt- 1 denotes the hydroelectric water reservoirs on day $\mathrm{t}-1$, and $\mathrm{PMO}_{\mathrm{t}-2, \mathrm{t}-1, \mathrm{i}}$ is the average supply price offered by the group of generators the day before (day $t-2)$ for delivering electricity on the day-ahead (day $t-1)$ during hour $i$. The stochastic component, $\mathrm{u}_{\mathrm{t}, \mathrm{i}}$, is a process made up of two components: $v_{\mathrm{i}}$, which is assumed to be independent over the days but allows for cross-sectional covariance between the hours and $\varepsilon_{\mathrm{t}, \mathrm{i}}$, which is the usual homoscedastic component, normally distributed $\mathrm{N}(0, \sigma)$. There are three panel data fixed-effect models, one for each generate on technology group. Combined cycle generators (CC), thermal (CT), hydraulics (CH). The significant codes (Sig.) are: $0^{‘ * * * \prime} 0.001^{‘ * * \prime}$ $0.01^{\prime * \prime} 0.05$ ' $0.1^{\prime \prime \prime} 1$. 
Table 8. Panel data pooling estimation.

\begin{tabular}{|c|c|c|c|c|c|c|}
\hline \multirow[b]{2}{*}{ Parameter } & \multicolumn{3}{|c|}{$\mathrm{CN}$} & \multicolumn{3}{|c|}{ CR } \\
\hline & Value & t-Statistic & Sig. & Value & t-Statistic & Sig. \\
\hline$\alpha$ & 6.90959 & 6.18 & $* * *$ & 2.55307 & 4.49 & $* * *$ \\
\hline$\beta$ & -0.00002 & -0.97 & & -0.00008 & -7.68 & $* * *$ \\
\hline$\gamma$ & 0.03202 & 0.24 & & -0.08613 & -1.54 & \\
\hline$\phi$ & 0.03684 & 0.90 & & -0.05055 & -1.60 & \\
\hline$\omega$ & -0.01684 & -2.66 & $* *$ & -0.00819 & -2.41 & $*$ \\
\hline$\delta$ & 0.72399 & 17.89 & $* * *$ & 0.93633 & 80.35 & $* * *$ \\
\hline $\mathrm{R}$-squared & 0.54326 & & & 0.91421 & & \\
\hline Adj.R-squared & 0.54320 & & & 0.91420 & & \\
\hline
\end{tabular}

$\mathrm{PMO}_{\mathrm{t}-1, \mathrm{t}, \mathrm{i}}=\alpha+\beta^{*} \mathrm{WPF}_{\mathrm{t}-1, \mathrm{t}, \mathrm{i}}+\gamma^{*} \mathrm{DL}_{\mathrm{t}}+\phi^{*} \mathrm{NG}_{\mathrm{t}-1} / \mathrm{EUA}_{\mathrm{t}-2}+\omega^{*} \mathrm{WRt}-1+\delta^{*} \mathrm{PMO}_{\mathrm{t}-2, \mathrm{t}-1, \mathrm{i}}+\varepsilon_{\mathrm{t}, \mathrm{i}}(2)$. Pooling panel linear models with nonparametric robust covariance matrix estimators for panel models with cross-sectional and serial correlation ([20]). $\mathrm{PMO}_{\mathrm{t}-1, \mathrm{t}, \mathrm{i}}$ is the average supply price offered by the group of generators sharing the same generation technology submitted on a particular day (day $t-1)$ for delivering electricity on the day-ahead (day $\mathrm{t}$ ) during hour $\mathrm{i} ; \mathrm{WPF}_{\mathrm{t}-1, \mathrm{t}, \mathrm{i}}$ denotes the wind power forecast made public on day $\mathrm{t}-1$ just before the deadline for submitting bids to the day-ahead market auction for delivering electricity during hour $i$ on day $t$; $D_{t}$ is a dummy variable that equals 1 if $t$ is a business day, and 0 , otherwise; $N_{t-1}$ is the British natural day-ahead trade close price on day $\mathrm{t}-1 ; \mathrm{EUA}_{\mathrm{t}-2}$ refers to the European emission allowances next December maturity futures closing prices on day $t-2 ; \mathrm{WR}_{t-1}$ denotes the hydroelectric water reservoirs on day $t-1$, and $\mathrm{PMO}_{\mathrm{t}-2, \mathrm{t}-1, \mathrm{i}}$ is the average supply price offered by the group of generators the day-before $($ day $t-2)$ for delivering electricity on the day-ahead (day $\mathrm{t}-1$ ) during hour $\mathrm{i}$. The stochastic component $\varepsilon_{t, i}$, which is the usual homoscedastic component, normally distributed $\mathrm{N}(0, \sigma)$. Nuclear $(\mathrm{CN})$ and renewable (CR). The significant codes (Sig.) are: $0^{\star * * * \prime} 0.001^{\prime * * \prime} 0.01^{\prime * \prime} 0.05^{\prime}$.' $0.1 " 1$.

\subsubsection{Wind Production Forecasts $(\beta)$}

The $t$-test for the significance of the coefficient that accompanies the WPF series $(\beta)$ indicates that the estimated $\beta$ parameter value is statistically significant for all generation technologies, implying that wind production forecasts have become relevant for all the supply market participants, with the only exception being $\mathrm{CN}$ plants which are shown to be indifferent with regards to expected wind production. Nuclear plants have the clear incentive to continuously generate electricity due to the high costs of stopping production. It is worth emphasising that the series of WPF employed in the present study corresponds to the last hourly series made public by REE just before the deadline for submitting bids for the day-ahead market-since this is the most informative series. The underlying idea is that generators are expected to consider the wind power forecasts when designing their trading strategies and consider the most updated predictions just before that deadline. An a priori expected result is a negative value of the $\beta$ parameter, given that the expected marginal price is supposed to decrease with increased wind production. Thereby, a logical reaction from bidders would consist in offering lower prices so as not to become unmatched, obviously without exceeding their own production costs. However, according to our results, the CT and CC plants would have been generally offering their production at higher prices when expecting increases in wind production, perhaps trying to compensate for the presumably lower income resulting from a less-likely required thermal and combined cycle production. The increase in the resulting marginal prices may be viewed as a wind premium for the risk of generating less electricity than usual, but at the same time, these generators would incur a risk of not being matched and so being dropped from the day-ahead auction.

\subsubsection{Business-Day Dummy $(\gamma)$ and Effects by Hour $\left(v_{\mathrm{i}}\right)$}

From Tables 7 and 8, the parameter value associated with the business dummy variable, $\gamma$, is significantly negative for CC and CT plants, whereas it is not statistically different from zero (at the $5 \%$ level) for $\mathrm{CN}, \mathrm{CH}$, and $\mathrm{CR}$ plants. The positive value of this parameter for $\mathrm{CN}$ plants implies that they would offer their production at higher prices for delivery hours on business days, when marginal prices are typically higher due to increased demand. However, the opposite holds for CC and CT plants. Therefore, these latter appear to bid at lower prices for business hours. 
As mentioned before, the data panel model for $\mathrm{CC}, \mathrm{CT}$, and $\mathrm{CH}$ generation technologies enables differentiation for the specific effects of each hour. Thus, the results are subsequently enriched with the $\mathrm{v}_{\mathrm{e}, \mathrm{i}}$ parameter value for each generation technology group e and hour i. Table 7 shows how it is found that CC and CT plants submit their bids to the market at higher prices during the early hours of the day (from the first to the sixth hour) when electricity demand levels are the lowest. It is of note that during these low demand periods, electricity is usually generated by plants with the lowest marginal costs because bids from the remaining plants are normally too high to determine the marginal price and they drop out of the auction. The differences in the hourly bids from $\mathrm{CH}$ plants are, on the contrary, very small. Regarding $\mathrm{CN}$ and $\mathrm{CR}$ plants, as previously explained, the pooling model is shown to be more suitable, which leads us to conclude that there is no evidence of differences in strategic bidding behaviour between hours from $\mathrm{CN}$ and $\mathrm{CR}$ plants.

\subsubsection{Natural Gas $/ \mathrm{CO}_{2}$ Price Ratio $(\phi)$}

The next step is to look at the effect of natural gas prices and carbon prices on the supply bids to the day-ahead market. Following previous literature, to avoid multicollinearity problems caused by correlation between explanatory variables, the ratio natural gas prices/carbon prices is chosen instead of considering these two series of prices separately, i.e., as individual independent variables. The natural gas and carbon price series selected are the corresponding international price benchmarks. The former corresponds to national balance point natural gas day-ahead prices on day $t-1$, whereas the carbon price series is the ICE ECX European emission allowances next December maturity closing futures prices at $t-2$. Regarding this latter price series, we use lagged prices because at the closure time of the day-ahead auction market which takes place at $t-1$ (for delivering electricity at $t$ ), the available closing prices are those of the previous trading session, i.e., at $\mathrm{t}-2$.

Coming back to Tables 7 and 8, there is statistical evidence that the so-defined ratio does have an impact on the prices offered by $\mathrm{CC}, \mathrm{CT}$, and $\mathrm{CH}$, according to the estimated $\phi$ parameter value, which is statistically different from zero. The resulting sign of this coefficient also offers interesting insights. Thus, it is positive for the $\mathrm{CC}$ and $\mathrm{CH}$, meaning that the offered prices by these plant groups would be increasing with natural gas prices and/or generally decreasing with carbon emission allowance prices. Given that CC plants use natural gas as fuel to generate electricity, they are negatively affected by increases in natural gas prices. The plants are then expected to incorporate this information into their bids as an extra cost. As this type of plant is usually among those that set the marginal price, whenever they need to generate electricity to satisfy the overall demand an increase in marginal price would be expected. However, under these market circumstances, $\mathrm{CH}$ plants, being reasonably sure that their bids will still be lower than those from CC plants, may behave strategically and submit higher bids than usual and seek to profit from higher marginal prices set by themselves.

In contrast, the sign of the estimated $\phi$ parameter is negative for $\mathrm{CT}$, indicating that they would offer higher prices when expecting lower natural gas prices and/or higher carbon emission allowance prices. This result is consistent with the fact that thermal plants, being the most pollutant technology, may have internalised the cost of paying for the carbon emission allowances into their bids and submit higher bid prices when expecting higher carbon prices.

\subsubsection{Hydroelectric Reservoir Levels ( $\omega$ )}

Hydroelectric plants enjoy an important advantage since they can easily adjust their production to the amount needed. Of course, the electricity they can produce depends on annual rainfall, and more specifically, on the water reservoir levels. As only weekly data was available, each datum is repeated for seven daily periods. The way in which larger reservoirs can impact on prices is very similar to that of increased wind. In fact, more reservoirs would imply more capacity to produce electricity and more supply. In times of water reservoir excess, hydroelectric generators, with very low variable costs, can bid into the auction market at lower prices. The obtained results are consistent with that idea, with the only exception being the coefficient for the thermal generation plants. In particular, the estimated $\omega$ 
parameter value is significantly negative for all the generation technology plant groups, meaning that bid prices will decrease with hydroelectric water reservoirs, except for the CT plants for which the estimated $\omega$ value is shown to be significantly positive.

\subsubsection{Lagged Dependent Variable ( $\delta)$}

Finally, the parameter $\delta$ of the lagged dependent variable is strongly significant for all technologies. In other words, the bid price is strongly influenced by the same bid price submitted the day before for the same hour.

Summarising the results, firstly, it is evidenced that expected wind power production has become a new price determinant, since it has been shown to impact on generator bidding strategies-with the only exception of CN. Secondly, because of variations in the wind production forecasts, natural gas prices, carbon prices, and hydroelectric reservoirs, the $\mathrm{CH}, \mathrm{CN}$, and $\mathrm{CR}$ plants generally behave as expected and consistently submit bids with the aim of being matched in the day-ahead auction market.

Nevertheless, according to our results, CC and CT plants offer their production at higher prices when there is a larger supply of low-cost electricity, i.e., assuming a higher risk of dropping out of the day-ahead auction. It has been shown that CC and CT plants submit bids at higher prices: (i) when wind production forecast is larger; (ii) on non-business days; and (iii) from hour 1 to hour 7-namely coinciding with low demand levels. CT plants also bid at higher prices when there is more water in the hydroelectric reservoirs.

\section{Quantifying the Impact of Wind Power Forecasts on the Marginal Price}

As shown in the previous section, supply bidders react to wind production forecasting in a different manner depending on the generation technology. Our aim here is to quantify the effect of this result on the marginal price level. To do so, we simulate the day-ahead hourly marginal prices by intersecting the actual (aggregate) demand curve and a fictitious (aggregate) supply curve built as follows:

$$
\hat{\mathrm{P}}_{\mathrm{ae}, \mathrm{t}-1, \mathrm{t}, \mathrm{i}}=\mathrm{P}_{\mathrm{ae}, \mathrm{t}-1, \mathrm{t}, \mathrm{i}}-\beta_{\mathrm{e}} \mathrm{WPF}_{\mathrm{t}-1, \mathrm{t}, \mathrm{i}}
$$

where $\hat{P}_{\mathrm{a} \in \mathrm{e}, \mathrm{t}-1, \mathrm{t}, \mathrm{i}}$ denotes the modified offered price; $\mathrm{P}_{\mathrm{a} \in \mathrm{e}, \mathrm{t}-1, \mathrm{t}, \mathrm{i}}$ is the actual offered price submitted on day $t-1$ by the market participant a of the generation technology group e for the hour $i$ of the delivery day $\mathrm{t} ; \beta_{\mathrm{e}}$ is the estimated parameter obtained for the generation technology group e (displayed in Tables 7 and 8 ), and $\mathrm{WPF}_{\mathrm{t}-1, \mathrm{t}, \mathrm{i}}$ is the wind power forecast, known at day $\mathrm{t}-1$, just before the deadline for submitting bids to the day-ahead auction market for hour i of day-ahead $t$. The simulation exercise covers the whole of 2013 and consists of intersecting the modified aggregate supply curve and the actual demand to obtain the simulated marginal price, isolating the impact of the wind power forecast on the bidding behaviour of each generation technology, and ultimately, on marginal prices. A total of $24 \times 5$ marginal prices were simulated. Differences between actual and simulated prices are displayed in Table 9.

The average actual daily marginal price during 2013 was 44.05 euro/MWh, whereas the average simulated marginal price after removing the estimated effect of the wind power forecast on the offered prices by the thermal generation group according to the Formula (3), amounts to 43.55 euro/MWh.

Therefore, the overall daily effect for the year 2013 that may be attributable to the thermal generation bids may be quantified, on average, at a minimum increase of 0.5 euros/MWh. Distinguishing between hours, the average increase in the marginal price oscillates between 0.68 euros/MWh in hour 17 and 0.26 euros/MWh in hour 3 (Table 9).

The overall daily effect for combined cycle plants also means an increase in prices of 0.06 euros/MWh (a maximum of 0.15 euros / MWh in the hour 24 and a minimum of -0.18 euros/MWh in hour 4). 
Table 9. Impact of the wind power forecast (WPF) on the marginal price.

\begin{tabular}{cccccc}
\hline & CC & CT & CH & CR & TOTAL \\
\hline Hour/daily average price & 0.06 & 0.50 & -0.39 & -0.22 & 0.16 \\
1 & 0.05 & 0.48 & -0.45 & -0.22 & 0.14 \\
2 & 0.03 & 0.48 & -0.38 & -0.29 & 0.18 \\
3 & -0.17 & 0.26 & -0.54 & -0.50 & -0.13 \\
4 & -0.18 & 0.31 & -0.49 & -0.50 & -0.02 \\
5 & -0.10 & 0.34 & -0.45 & -0.46 & 0.04 \\
6 & -0.03 & 0.44 & -0.38 & -0.35 & 0.16 \\
7 & 0.03 & 0.59 & -0.25 & -0.27 & 0.33 \\
8 & 0.08 & 0.55 & -0.33 & -0.18 & 0.28 \\
9 & 0.07 & 0.55 & -0.31 & -0.22 & 0.25 \\
10 & 0.06 & 0.43 & -0.45 & -0.15 & 0.10 \\
11 & 0.12 & 0.48 & -0.40 & -0.13 & 0.15 \\
12 & 0.12 & 0.47 & -0.40 & -0.16 & 0.14 \\
13 & 0.13 & 0.49 & -0.42 & -0.14 & 0.13 \\
14 & 0.12 & 0.54 & -0.35 & -0.15 & 0.20 \\
15 & 0.11 & 0.57 & -0.36 & -0.19 & 0.22 \\
16 & 0.14 & 0.63 & -0.33 & -0.17 & 0.31 \\
17 & 0.13 & 0.68 & -0.33 & -0.16 & 0.35 \\
18 & 0.14 & 0.61 & -0.32 & -0.17 & 0.26 \\
19 & 0.12 & 0.63 & -0.39 & -0.17 & 0.23 \\
20 & 0.11 & 0.49 & -0.41 & -0.14 & 0.06 \\
21 & 0.12 & 0.48 & -0.43 & -0.13 & 0.00 \\
22 & 0.13 & 0.49 & -0.43 & -0.12 & 0.03 \\
23 & 0.09 & 0.53 & -0.40 & -0.13 & 0.10 \\
24 & 0.15 & 0.63 & -0.28 & -0.15 & 0.39 \\
\hline
\end{tabular}

It displays the difference between the actual marginal price and the simulated spot price, distinguishing by generation technology group. The daily difference is shown together with the difference per hour for the whole year 2013. Combined cycle generators (CC), thermal (CT), hydroelectric $(\mathrm{CH})$, and renewable (CR).

As the beta value for the remaining generation technology plant groups is statistically negative, the effect of their reaction to wind production forecasts leads to a decrease in the estimated marginal prices. On average, the decrease in the marginal price attributable to $\mathrm{CH}$ and $\mathrm{CR}$ generation groups bidding when reacting to the wind production forecasts, would have respectively been of -0.39 euros/MWh and -0.22 euros/MWh.

In short, the overall effect of the generator bidding strategies linked to the wind production forecasts for the simulated sample period (year 2013) was an increase in average marginal prices. Hence, the impact of such strategies is shown to be large enough to overwhelm the well-known merit order effect of renewables.

\section{Discussion and Concluding Remarks}

The purpose of this work is to analyse the way in which the bidding strategies by generators have been conditioned by expected wind production, among other key variables, in the Spanish electricity day-ahead market (which has experienced a continuously increasing proportion of wind power in the electricity generation mix).

To summarise the results, expected wind production is a new price determinant and is shown as relevant for the considered supply side participants when submitting their bids to the day-ahead auction market. Nuclear generators are the only exception, as they cannot afford to stop production and so lack the flexibility to maximise profits by bidding strategically.

The average prices offered by CC and CT plants for a given hour have proved to be systematically higher when expected demand levels are low for the studied sample (when delivery is taking place on a non-business day and for the first seven delivery hours of business and non-business days). These results can make sense for generation plants with low variable costs and enough flexibility (such as CR 
or $\mathrm{CH}$ plants) since it is in situations of low demand when they tend to submit less aggressive bids and profit from higher prices if they are successful in setting the marginal price. Anticipating that during these low-demand hours, the electricity produced by $\mathrm{CN}, \mathrm{CH}$, and $\mathrm{CR}$ generation plants will likely be sufficient to meet demand, the bids submitted by these generators can push the marginal price upward. However, it is a priori difficult to establish why CC and CT, with much higher variable costs, bid higher prices when expected demand levels remain low, so incurring the risk of dropping from the auction.

According to the obtained results, the case of CT generation plants deserves a special mention, since they seem to submit bids at higher prices when: (i) the ratio natural gas/carbon price is expected to be lower, which is a logical result given that expected higher carbon prices may imply higher costs precisely for these generation plants; but also when (ii) wind production forecast is greater; and when (iii) there is more water in the hydroelectric reservoirs. Additionally, as mentioned above, their offered prices are higher, on average, for non-business days and from hour 1 to hour 7 .

These results seem to lead to counterintuitive conclusions; however, it does not need to be so. As is generally known, the spot electricity market is made up of several sequential trading markets. Market participants submit their bids to buy or sell electricity for each of the $24 \mathrm{~h}$ of the following day through the day ahead market, which is usually the most liquid market and whose price serves as the benchmark for forward contracts. However, given the nature of electricity, the result of the day-ahead 24 auctions must also be feasible from a technical point of view. In the Spanish case, it is the system operator (R.E.E.) who takes the responsibility for validating the technical viability of the day-ahead auction results, as well as for guaranteeing an annually fixed share of domestic coal for producing electricity to reduce external dependence within the supply security constraint regulation process. It is possible for market participants to rectify their previously open positions in the intraday market, which is a balancing market structured into six new consecutive auction markets. In addition, the system operator also manages several additional regulated markets to solve real-time deviations.

Therefore, the possibility of trading in sequential markets with different prices and/or the possibility of being required to produce electricity (to solve technical constraints, to assure a predetermined level of production by using domestic coal, or to guarantee system security in exchange for prices different from the resulting marginal price in the day-ahead market) may lead generators to coordinate bidding in the day-ahead, and subsequently, balancing regulated markets or processes.

Moreover, if these latter prices are systematically higher than the day-ahead market price then generators may prefer to hold back capacity in the day-ahead market to facilitate subsequent offerings in the next sequential markets, or other processes in which they can participate. The fact that market participants may consider the outcome of the sequence of markets, and not each market in isolation, was addressed by [24] for the Californian market. Also for the Spanish case, [25] pointed out that some generation plants could have been submitting sale orders in the day-ahead market at high prices that would not be matched-and so that they would finally be required to produce electricity to solve congestion. This approach would have been more profitable according to the regulations in force during the period in question (from July 2004 to February 2005). In [26], the potential of coordinated bidding in the spot and balancing markets was investigated and it was concluded that significant profits could be made from such a coordination for the Nord Pool.

Concerning the results of the simulation exercise to quantify the effect of wind power forecasts on the day-ahead marginal price, the overall effect for the year 2013 was shown to be negative for electricity consumers, since the aggregated impact of the bidding strategies carried out by the $\mathrm{CH}$ and $\mathrm{CR}$ generation plant groups (offering lower prices for low-demand-level delivery periods) may have pushed marginal prices down (consistent with the merit-order effect of renewables) but did not overwhelm the increase in marginal prices produced by the effect of the bidding strategies implemented by the CT and CC generation plant groups. 
The findings obtained in the present work are of interest to practitioners and regulators, given that they shed light on how the inclusion of renewable generation in the electricity market has altered the trading strategies of the supply market participants in the day-ahead market.

The strong presence of renewable generation in many power markets entails changes in power system planning, operating, and monitoring. These changes need to be considered and adapted to the operational processes. Conventional technologies such as thermal or combined cycle plants have been displaced by wind or solar generation that is characterised by flexibility and significantly lower variable costs of production. In addition, non-flexible conventional generation plants incur high operating and maintenance costs when starting and shutting down. In those cases, where storage capabilities such as hydro resources are insufficient, conventional generation plants may be useful in providing operating reserves as a backup generation to manage the intermittency of renewable generation, or for guaranteeing system security by resolving output forecasting errors in the renewable generation models used for planning the day-ahead plant schedules.

In [27], the European Commission pointed out that the economic impact of balancing costs needs to be considered in well-designed renewable support schemes. For as long as renewable generation continues to be intermittent and wind output forecasts for periods other than very short-term are insufficiently accurate, then three (related) crucial issues will be: (i) assessing and revising the design of balancing rules considering the particularities of all the generation technologies involved; (ii) determining the amount of operating reserves needed to keep the power system functioning securely; and (iii) revising the way these backup reserves should be remunerated and providing the appropriate incentives as market signals to incumbent and new entrants that may lead to more efficient operations in the whole electricity market.

Our results suggest that some conventional generators react to the entrance of renewable generating sources by behaving in a somewhat strategic manner that contributes to pushing up marginal prices, and thereby creating a wind risk premium that should be considered by regulators when thinking about changes in regulation or market design to adapt to the new market situation. Furthermore, as the need for balancing power is expected to increase with the growth of fluctuating renewable production, an analysis of coordinated bidding in the day-ahead and subsequent markets, as well as in the provision of balancing services for the Spanish case, would also be of interest. This is left for further research.

Acknowledgments: The authors wish to thank Hipòlit Torró, Constantino J. García, and the participants at the 6th Research Workshop on Energy Markets for their valuable comments, as well as the financial support of the Spanish Ministry of Education and Science (project ECO2013-40816-P).

Author Contributions: Cristina Ballester and Dolores Furió conceived and designed the experiments; Cristina Ballester performed the experiments; Dolores Furió verified the results; Cristina Ballester and Dolores Furió wrote the paper.

Conflicts of Interest: The authors declare no conflict of interest.

\section{References}

1. Holttinen, H. The Impact of Large Scale Wind Power Production on the Nordic Electricity System. Ph.D. Thesis, Helsinki University of Technology, Espoo, Finland, 2004.

2. Sensfuß, F.; Ragwitz, M.; Genoese, M. The merit-order effect: A detailed analysis of the price effect of renewable electricity generation on spot market prices in Germany. Energy Policy 2008, 36, 3086-3094. [CrossRef]

3. De Miera, G.S.; Del Río, P.; Vizcaíno, I. Analyzing the impact of renewable electricity support schemes on power prices: The case of wind electricity in Spain. Energy Policy 2008, 36, 3345-3359. [CrossRef]

4. Green, R.; Vasilakos, N. Market behaviour with large amounts of intermittent generation. Energy Policy 2010, 38, 3211-3220. [CrossRef]

5. Gelabert, L.; Labandeira, X.; Linares, P. An ex-post analysis of the effect of renewables and cogeneration on Spanish electricity prices. Energy Econ. 2011, 33, S59-S65. [CrossRef] 
6. Gil, H.A.; Gomez-Quiles, C.; Riquelme, J. Large-scale wind power integration and wholesale electricity trading benefits: Estimation via ex post approach. Energy Policy 2012, 41, 849-859. [CrossRef]

7. Ballester, C.; Furió, D. Effects of Renewables on the Stylized Facts of Electricity Prices. Renew. Sustain. Energy Rev. 2015, 52, 1596-1609. [CrossRef]

8. Di Cosmo, V.; Malaguzzi, L. Wind, Storage, Interconnection and the Cost of Electricity Generatio. Available online: https:/ / papers.ssrn.com/sol3/papers.cfm?abstract_id=2926875 (accessed on 18 July 2017).

9. Würzburg, K.; Labandeira, X.; Linares, P. Renewable generation and electricity prices: Taking stock and new evidence for Germany and Austria. Energy Econ. 2013, 40, S159-S171. [CrossRef]

10. Weidlich, A.; Veit, D. A critical survey of agent-based wholesale electricity market models. Energy Econ. 2008, 30, 1728-1759. [CrossRef]

11. Gountis, V.P.; Bakirtzis, A.G. Bidding strategies for electricity producers in a competitive electricity marketplace. IEEE Trans. Power Syst. 2004, 19, 356-365. [CrossRef]

12. Veit, D.J.; Weidlich, A.; Krafft, J. An agent-based analysis of the German electricity market with transmission capacity constraints. Energy Policy 2009, 37, 4132-4144. [CrossRef]

13. Twomey, P.; Neuhoff, K. Wind power and market power in competitive markets. Energy Policy 2010, 38, 3198-3210. [CrossRef]

14. Jónsson, T.; Pinson, P.; Madsen, H. On the market impact of wind energy forecast. Energy Econ. 2010, 32, 313-320. [CrossRef]

15. Li, G.; Shi, J. Agent-based modelling for trading wind power with uncertainty in the day-ahead wholesale electricity markets of single-sided auctions. Appl. Energy 2012, 99, 13-22. [CrossRef]

16. Ciarreta, A.; Espinosa, M. Supply Function Competition in the Spanish Wholesale Electricity Market. Energy J. 2010, 31, 4, 137-157. [CrossRef]

17. Green, W.H. Econometric Analysis, 5th ed.; Prentice Hall: Upper Saddle River, NJ, USA, 2002.

18. Hall, S.; Urga, G. New Developments in the Analysis of Panel Data Sets. The Current State of Business Disciplines. Bus. Econ. 2000, 2, 537-564.

19. Maddala, G.S.; Wu, S. A Comparative Study of Unit Root Tests with Panel Data and a New Simple Test. Oxf. Bull. Econ. Stat. 1999, 61 (Suppl. 1), 631-652. [CrossRef]

20. Driscol, J.; Kraay, A. Consistent Covariance Matrix Estimation with Spatially Dependent Panel Data. Rev. Econ. Stat. 1998, 80, 549-560. [CrossRef]

21. Cameron, A.; Miller, D. A practioner's Guide to Cluster-Robust Inference. Hum. Resour. 2015, 317-372. [CrossRef]

22. Arellano, M. Computing Robust Standard Errors for Within-groups Estimators. Oxf. Bull. Econ. Stat. 1987, 49,4 .

23. Cameron, A.; Gelbach, J.; Miller, D. Bootstrap-Based Improvements for Inference with Clustered Errors. Rev. Econ. Stat. 2008, 90, 414-427. [CrossRef]

24. Borenstein, S.; Bushnell, J.A.; Knittle, C.; Wolfram, C. Inefficiencies and Market Power in Financial Arbitrage: A Study of California's Electricity Markets. Available online: http:/ / onlinelibrary.wiley.com/doi/10.1111/j. 1467-6451.2008.00344.x/full (accessed on 18 July 2017).

25. Furió, D.; Lucia, J. Congestion management rules and trading strategies in the Spanish electricity market. Energy Econ. 2009, 31, 48-60. [CrossRef]

26. Boomsma, T.K.; Juul, N.; Fleten, S.-E. Bidding in sequential electricity markets: The Nordic case. Eur. J. Oper. Res. 2014, 238, 797-809. [CrossRef]

27. European Commission. Commission Staff Working Paper (SWD) 2013, 439. Available online: http: / / eur-lex. europa.eu/legal-content/EN/TXT/?uri=CELEX\%3A52013SC0493\%2801\%29 (accessed on 18 July 2017).

(C) 2017 by the authors. Licensee MDPI, Basel, Switzerland. This article is an open access article distributed under the terms and conditions of the Creative Commons Attribution (CC BY) license (http:/ / creativecommons.org/licenses/by/4.0/). 